\title{
The effects of positive schizotypy and sleep deprivation on prepulse inhibition
}

Inga Meyhöfer (1,2), Ulrich Ettinger (1)*, Eliana Faiola (1), Nadine Petrovsky (1), Veena Kumari (3)

(1) Department of Psychology, University of Bonn, Bonn, Germany

(2) Department of Psychiatry, University of Münster, Münster, Germany

(3) Centre for Cognitive Neuroscience, College of Health and Life Sciences, Brunel University London, Uxbridge, UK

\section{*Correspondence:}

Ulrich Ettinger, Department of Psychology, University of Bonn, Kaiser-Karl-Ring 9, 53111 Bonn, Germany, Email: ulrich.ettinger@uni-bonn.de, Phone: +49 228734208

\section{Count Words}

Abstract: 205

Text Body: 2853

\section{Acknowledgements and Conflicts of Interest}

V.K. acknowledges receipt of a Humboldt Research Award. Furthermore, we thank Ann-Kathrin Arnold, Christian Burk, Eva Freda, Tristan Hencke, Linda Ludewigs, Hülya Öztürk, Marie Rundholz, Jörg Wester, and Yvonne Winter for their assistance in data collection. We are grateful to all volunteers who participated in the study.

\section{Contributions}

U.E., N.P., and V.K. designed research; I.M. and E.F. performed research; I.M., U.E., and V.K. analyzed the data; I.M., U.E., and V.K. wrote the paper. All authors contributed to and have approved the final manuscript. 


\section{ABSTRACT}

Prepulse inhibition (PPI) of the startle response is a measure of sensorimotor gating. PPI deficits have been reported in schizophrenia patients, their first-degree relatives, and in schizotypal individuals. Reduced PPI has also been observed in rodent and human experimental model systems of psychosis, such as acute sleep deprivation. In this study, we aimed to replicate the effects of schizotypy and sleep deprivation on PPI and investigated, for the first time, their interactive effects. To do so, 24 participants, 12 with high positive schizotypy and 12 with low-to-moderate schizotypy (controls), were measured after nights of normal sleep and 24-hour total sleep deprivation. An interaction between schizotypy group and stimulus onset asynchrony (SOA) $(p=.03)$ indicated lower PPI at $60 \mathrm{~ms}$ and $120 \mathrm{~ms}$ SOAs for schizotypes than controls. Schizotypes also had lower startle amplitude than controls $(p=.02)$. In line with previous data, sleep deprivation reduced PPI although this effect missed formal significance $\left(p \geq .07 ; \eta_{p}{ }^{2}=0.14\right)$. There were no interactions involving schizotypy, sleep deprivation or SOA on PPI ( $p>.6$; all effect sizes negligible). We conclude that both positive schizotypy and sleep deprivation provide valid human model systems that in combination with the widely studied cross-species biomarker PPI demonstrates a valuable tool to advance the development of pro-cognitive drugs in the treatment of psychotic disorders. Their effects in PPI, however, appear to be mediated by different mechanisms.

\section{KEYWORDS}

Psychosis, schizophrenia, schizotypy, sleep deprivation, model system, prepulse inhibition 


\section{INTRODUCTION}

Prepulse inhibition (PPI) refers to a reduction in response to a startling pulse when it follows a weak non-startling prepulse with a short stimulus onset asynchrony (SOA) (Graham, 1975). PPI is considered a measure of sensorimotor gating that helps to protect the processing of the initial stimulus (the prepulse) (Braff and Geyer, 1990). Reduced PPI in schizophrenia was first reported by Braff and colleagues (Braff et al., 1978) and since then many studies have replicated deficits in unmedicated first-episode (Kumari et al., 2007; Ludewig et al., 2003) and medicated (Swerdlow et al., 2014, 2006) schizophrenia patients. Additionally, lower PPI has been found in their first-degree relatives (Cadenhead et al., 2000; Kumari et al., 2005), in patients with schizotypal personality disorder (Cadenhead et al., 2000, 1993), and individuals with high-risk status (De Koning et al., 2014; Ziermans et al., 2011). Overall, there is thus convincing evidence that PPI is an endophenotype for psychosis spectrum disorders (Gottesman and Gould, 2003).

Based on these findings, PPI has been employed as translational surrogate marker in the development of antipsychotic and pro-cognitive drugs (Green et al., 2009; Swerdlow et al., 2008), when combined with psychosis model systems (Geyer, 2008). These model systems include trait (e.g., schizotypy; Evans et al., 2005)) and state (e.g., sleep deprivation; Petrovsky et al., 2014) models. They are tools in detecting early indicators of effectiveness in the development of new compounds and further our understanding of the etiology of psychosis symptoms (Ettinger et al., 2014; Ettinger and Kumari, 2015).

Schizotypy refers to a pattern of time-stable multidimensional traits (Mason et al., 1995; Raine et al., 1994) that resembles the positive (e.g., unusual perceptual experiences), negative (e.g., lack of enjoyment from social sources), and disorganized (e.g., odd speech and eccentric behavior) symptoms of psychosis in an attenuated form (Barrantes-Vidal et al., 2015; Nelson et al., 2013). The majority of previous studies that examined PPI in schizotypy-related traits (Kumari et al., 2008, 1997; Swerdlow et al., 1995; Takahashi et al., 2010), found it be reduced (however see Abel et al., 2004; 
Blumenthal and Creps, 1994) with deficits most pronounced in the positive and cognitive dimensions (Evans et al., 2005; Simons and Giardina, 1992).

Acute sleep deprivation is a potential experimental model of psychosis (Ettinger and Kumari, 2015) as it has been shown to induce perceptual aberrations similar to positive (e.g., perceptual alterations), negative (disinterest in the outside world), and disorganized (confusion, disorientation) symptoms (Berger and Oswald, 1962; Kahn-Greene et al., 2007; Kollar et al., 1969; Luby et al., 1962; West et al., 1962). Additionally, sleep deprivation was shown to disrupt PPI in rats (Chang et al., 2014; Frau et al., 2008) and humans (Petrovsky et al., 2014). PPI reductions after sleep deprivation in rats could be reversed by antipsychotic but not anxiolytic or antidepressant drugs (Frau et al., 2008).

Despite the positive evidence concerning schizotypy and sleep deprivation, nothing is known about the interactive effects of these putative models of psychosis. Investigating interactive effects of several models is important, as any one model system may not be sufficient to fully model psychosis symptoms, given the complexity and heterogeneity of the clinical disorder (Carhart-Harris et al., 2013). Thus, the combination of a trait and a state model system may more closely model the pathophysiology of psychosis. The aims of the current study were, therefore, to replicate (1) our previous finding of reduced PPI and elevated psychotomimetic states after sleep deprivation (Petrovsky et al., 2014), and (2) schizotypy-related PPI deficits (Simons and Giardina, 1992), and, in addition, examine, for the first time, potential interactions between schizotypy and sleep deprivation to affect PPI.

\section{METHOD}

\subsection{Participant Acquisition and Selection Criteria}

Healthy volunteers were recruited via flyers distributed locally and advertisements placed in social media forums. They were asked to complete an online version of the German translation of the Oxford-Liverpool Inventory of Feelings and Experiences short form (O-LIFE; Grant et al., 2013; Mason et al., 2005); online sample (Meyhöfer et al., 2017b), N=3356 females: Unusual Experiences, 
mean=5.09, standard deviation=3.07; Introvertive Anhedonia, mean=3.22, standard deviation=2.13; $\mathrm{N}=1652$ males, Unusual Experiences, mean=4.51, standard deviation=2.19; Introvertive Anhedonia, mean=3.67, standard deviation=2.19).

High schizotypes were required to score $\geq 1.25$ standard deviations above their same sex mean score on the Unusual Experiences subscale (female: $\geq 9$; male: $\geq 9$ ). Controls had to score $\leq 0.5$ standard deviations below their same sex mean scores on Unusual Experiences (female: $\leq 3$; male: $\leq 3)$. In addition, both groups were required to score $\leq 0.50$ standard deviations below the same sex mean on Introvertive Anhedonia (female: $\leq 2 ;$ male: $\leq 2$ ) to ensure no confounding effect of negative schizotypy.

Exclusion criteria were aged $<18$ or $>50$, first language other than German, any diagnoses of psychotic disorders among first-degree relatives (Neill, 2014), any hearing impairment, any prescription or over-the-counter medication (except for oral contraceptives and vitamins), any sleep disorder (either an established clinical diagnosis or self-reported continuous disturbances), irregular sleep-wake-rhythm, shift-working, any current Axis I disorder diagnosis and any current or history of psychotic disorders (MINI International Neuropsychiatric Interview; Sheehan et al., 1998), and current alcohol (ACE AL5500) or drug consumption (Drug-Screen Multi 5T, nal von minden GmbH).

The study was approved by the ethics committee of the Department of Psychology, University of Bonn. Participants provided written informed consent and were reimbursed with $€ 80$ or course credits.

\subsection{Study Procedure}

After completion of the online questionnaire, suitable participants were contacted via e-mail and screened for exclusion criteria via telephone. The laboratory sessions, including a night of normal sleep and a night of total sleep deprivation, were conducted one week apart and used a randomized counterbalanced within-subjects design described in detail previously (Meyhöfer et al., 2017b). 
Psychotomimetic states were measured in the evening before $(08: 30 \mathrm{pm})$ and the morning after (11:30 am) nights of normal sleep and total sleep deprivation. A battery of questionnaires and cognitive measures, including PPI, was conducted in the mornings after normal sleep and sleep deprivation (08:00 am to $11: 30 \mathrm{am})$. The results in the current study comprise a subsample $(n=24)$ of the sample ( $n=36$ ) reported in a previous publication (Meyhöfer et al., 2017b), with 12 high positive schizotypes and 12 controls who met inclusion criteria for the PPI experiment (three participants excluded due to hearing impairments) and provided usable data (measurable startle response on $>60 \%$ of pulse-alone trials). For further information on the selection process see Supplementary Table 2).

\subsection{Measurement of Psychotomimetic States}

Psychotomimetic states were quantified with the Psychotomimetic States Inventory (PSI; Mason et al., 2008), which yields the Delusional Thinking, Perceptual Distortion, Cognitive Disorganization, Anhedonia, Mania, and Paranoia subscales. Due to rare missing values (6 values in total), no imputation method was applied.

\subsection{Measurement of Prepulse Inhibition}

PPI was assessed with an electromyographic (EMG) startle system (Mark II; SR-Lab) that was used to provide acoustic startle stimuli and record EMG activity (digital units, 1 unit=2.62 $\mu \mathrm{V}$ ). Participants were seated in a comfortable chair and were instructed that they would hear white noise and bursts binaurally over headphones (TDH-39-P; Maico, Eden Prairie, Minnesota). No specific instructions were given on whether to attend the bursts or ignore them. Silver/silver chloride electrodes were applied below and next to the lateral canthus of the right eye over the orbicularis oculi muscle. A ground electrode was positioned on the glabella.

The task consisted of pulses ( $115 \mathrm{~dB}$ white-noise sound pulse, $40 \mathrm{~ms}$ ) that were presented either alone or after a prepulse (intensities $78 \mathrm{~dB}$ and $85 \mathrm{~dB}$, each $20 \mathrm{~ms}$ ). SOAs between prepulse and pulse were 30,60 or $120 \mathrm{~ms}$. The PPI session consisted of five blocks in total, whereas the first and 
the last block were five pulse-alone trials each. Blocks 2-4 comprised 21 trials each including three trials for each of the prepulse conditions and three pulse-alone trials presented in a pseudorandomized order. The inter-trial interval ranged between 9-22 seconds with a mean duration of 14 seconds. The duration of the PPI session was approximately 21 minutes (Petrovsky et al., 2014).

EMG activity was recorded for $250 \mathrm{~ms}$ (1ms interval) from stimulus onset and band-pass filtered. High- and low-pass cutoff frequencies were set at $30 \mathrm{~Hz}$ and $1 \mathrm{kHz}$. The amplification gain control was kept constant for all subjects. EMG data were first inspected trial by trial and then scored off-line using a rolling average routine that rectified and smoothed (window size $=10 \mathrm{~ms}$ ) the digitized response. For calculation of baseline and definition of response onset, recommended settings by SRLab were used. Trials were discarded if amplitude was zero, movement was detected during baseline (shift $>50$ units), or difference between onset and peak latency exceeded $95 \mathrm{~ms}$. Participants had to reach at least four trials in each condition and SOA for their data to be included into analyses.

Formulae for computing dependent variables followed previous studies (Kumari et al., 2008; Petrovsky et al., 2014, 2013): \% Early habituation: 100×[(pulse-alone startle amplitude 1. block-pulse-alone startle amplitude 2. block)/pulse-alone startle amplitude 1. block]; \% Total habituation: 100×[(pulse-alone startle amplitude 1. block-pulse-alone startle amplitude 5 . block)/pulse-alone startle amplitude 1. block]; Habituation coefficient was estimated using the slope in linear regression analysis ( $\mathrm{x}=$ block, $\mathrm{y}=$ pulse-alone startle amplitude); \% PPI=100×[(pulse-alone startle amplitude-prepulse-pulse amplitude)/pulse-alone startle amplitude]. PPI was computed using the average pulse-alone startle amplitude of blocks 2-4.

To avoid effects of nicotine intake (Kumari et al., 1996) and withdrawal (Kumari and Gray, 1999), cigarette smokers ( $n=4$ schizotypes, $n=1$ control subject) were allowed to smoke normally until two hours before the cognitive test battery started. 


\subsection{Statistical Analyses}

Data analyses were performed using the Statistical Package for the Social Sciences Version 23 (IBM Corporation, USA) and R (R Core Team, 2016). Startle amplitude was subjected to mixed ANOVA with Condition (normal sleep, sleep deprivation) and $\operatorname{Block}(1,2,3,4,5)$ as within-subjects factors and Group (high schizotypes, controls) as between-subjects factor. Habituation measures were analyzed in a mixed ANOVA with Condition (normal sleep, sleep deprivation) as within-subjects factor and Group (high schizotypes, controls) as between-subjects factor. Mean PPI was evaluated using a mixed ANOVA with Condition (normal sleep, sleep deprivation) and SOA (30ms, 60ms, 120ms) as within-subjects factors and Group (high schizotypes, controls) as between-subjects factor. Based on previous results (Petrovsky et al., 2014), PPI was averaged over prepulse intensities to achieve a more parsimonious model. Significant interactions involving the factor Group were followed up by one-tailed t-tests (Simons and Giardina, 1992) and significance was evaluated using Bonferroni-Holmcorrection (Holm, 1979).

PSI subscales were analyzed using a mixed ANOVA with Condition (normal sleep, sleep deprivation) and Time (pre-night, post-night) as within-subjects factors and Group (high schizotypes, controls) as between-subjects factor. Significant interactions between Condition and Time were followed up by one-tailed t-tests (Meyhöfer et al., 2017a) and post hoc tests were reported using Bonferroni-Holm-correction (Holm, 1979). The current PSI results roughly correspond to the results of the entire sample (Meyhöfer et al., 2017b) and are therefore presented only in the Supplementary Material.

To ensure that assumptions for parametric statistical analyses were accomplished, dependent variables were screened for violation of normality (Shapiro and Wilk, 1965) and homogeneity of variances (Glass, 1966). Greenhouse-Geisser correction (Jennings, 1987) was applied to adjust for violation of sphericity assumption. 
Effect sizes for ANOVAs were estimated using partial eta-squared (Cohen, 1973). Effect sizes for independent post hoc t-tests were given using Cohen's $d$ (Cohen, 1988), using an adapted version for repeated measures (Gibbons et al., 1993). Both options were computed with the R package effsize (Torchiano, 2016).

Two-tailed correlations were carried out to investigate whether startle amplitude and PPI are correlated. To do so, startle amplitude was averaged over blocks 2-4 and analyzed separately for the two groups. Significant correlations were evaluated using Bonferroni-Holm-correction (Holm, 1979).

To compare the results of the current to our previous study (Petrovsky et al., 2014), Cohen's $d$ (Gibbons et al., 1993) was calculated independent from schizotypy group, separately for the three SOAs in each of the two studies using the R package effsize (Torchiano, 2016).

\section{RESULTS}

\subsection{Data Prescreening}

Startle amplitude was markedly skewed and had to be log transformed in order to reach approximate normality. Descriptive statistics are presented in Table 2. Full summaries of the ANOVA and correlation analyses are presented in Supplementary Tables 2-5.

\subsection{Startle Amplitude and Habituation}

The ANOVA on startle amplitude revealed a main effect of Group $(F[1,19]=6.46, p=.02$, $\left.\eta_{\mathrm{p}}{ }^{2}=0.25\right)$, indicating lower amplitude in schizotypes than controls. Additionally, there was a main effect of Block $\left(F[4,76]=55.02, p<.001, \eta_{\mathrm{p}}{ }^{2}=0.74\right)$, suggesting startle habituation across the first three blocks (block 1>block 2, $p=.004, d=1.32$; block 2>block 3, $p=.004, d=1.53$; block 3=block 4, $p=.87$, $d=0.17$; block 4=block $5, p=.87, d=0.04$ ). No other effects were significant (all $p>.14$ ). Early habituation, total habituation and the habituation coefficient did not differ significantly between schizotypes and controls or between sleep and sleep deprivation (all $p>.24$ ). 


\subsection{PPI}

For PPI, there was an interaction between Group and $S O A\left(F[2,44]=4.00, p=.03, \eta_{\mathrm{p}}{ }^{2}=0.15\right.$, Figure 1), indicating lower PPI for schizotypes than controls at $60 \mathrm{~ms}(p=.03, d=0.94)$ and $120 \mathrm{~ms}$ $(p=.03, d=1.04)$ SOAs but not at 30ms SOA $(p=.30, d=0.22)$. The main effect of sleep deprivation was in the expected direction but failed to reach formal significance $\left(F[1,22]=3.60, p=.07, \eta_{\mathrm{p}}^{2}=0.14\right)$ and there were no interaction effects (Condition $\times$ SOA: $F[2,44]=0.22, \varepsilon=0.65, p=.71, \eta_{\mathrm{p}}{ }^{2}=0.01$ ) involving sleep deprivation. Furthermore, there were no interactive effects of schizotypy and sleep deprivation (Condition $\times$ Group: $F[1,22]=0.21, p=.65, \eta_{\mathrm{p}}{ }^{2}=0.01$; Condition $\times$ Group $\times S O A: F[2,44]=0.29, \varepsilon=0.65, p=.65$, $\left.\eta_{\mathrm{p}}{ }^{2}=0.01\right)$

\subsection{Correlations between Startle Amplitude and PPI}

In the high schizotypy group, lower startle amplitude was associated with lower PPI at 30ms SOA ( $p=.03), 60 \mathrm{~ms} \mathrm{SOA}(p=.003)$, and $120 \mathrm{~ms}$ SOA $(p=.004)$ after normal sleep (Figure 2$)$. There were no significant associations for high schizotypes after sleep deprivation ( $p>09)$. Additionally, startle amplitude was not related to PPI in the control group after normal sleep $(p>30)$ or after sleep deprivation ( $p>.99)$.

\section{DISCUSSION}

The goal of the current study was to investigate the schizotypy and sleep deprivation model systems of psychosis using PPI as a biomarker. In addition to providing a replication of previous schizotypy and sleep deprivation studies, we aimed to reveal, for the first time, potential interactions between these model systems. To do so, we investigated PPI in high positive schizotypes and lowschizotypy controls following nights of normal sleep and sleep deprivation.

High schizotypes displayed lower PPI in the $60 \mathrm{~ms}$ and $120 \mathrm{~ms}$ SOAs compared to low schizotypes. Our results are consistent with previous findings of lower PPI in positive schizotypy (Simons and Giardina, 1992; Takahashi et al., 2010) and the widely replicated PPI reductions in schizophrenia patients (Düring et al., 2014; Kumari et al., 2007), especially at 60ms SOA (Swerdlow et 
al., 2014, 2006). Overall, these findings support the notion of an overlap at cognitive and neural levels between schizophrenia and schizotypy (Ettinger et al., 2014).

High schizotypes also showed lower startle reactivity, a factor that might influence the interpretation of the PPI results. Previously, PPI has been found to depend on baseline startle amplitude; specifically, lower startle amplitude was associated with stronger PPI (Csomor et al., 2008). However, in the current study, positive schizotypes displayed lower startle amplitude as well as weaker PPI at $60 \mathrm{~ms}$ and $120 \mathrm{~ms}$ SOAs. A similar pattern has previously been found in people with high schizotypy (Simons and Giardina, 1992) and in unaffected biological siblings of schizophrenia patients (Kumari et al., 2005).

In our previous study (Petrovsky et al., 2014), we observed significantly reduced PPI following 24-hour sleep deprivation in $N=24$ healthy volunteers. That study provided the first observation of this effects in humans, thereby extending the findings from rodent studies (Frau et al., 2008). In this study, we employed the same PPI paradigm as in the previous study and an identical sleep deprivation procedure. Although the effect of sleep deprivation fell short of formal levels of statistical significance $(p=0.07)$ in this study, it was present with similar effect sizes to that seen in our earlier study (Table 3).

We found no significant interaction between schizotypy and sleep deprivation. This null effect is unlikely to be explained by the small sample size since there was no hint for a differential effect of sleep deprivation in PPI of schizotypes and controls (Table 2). Although there was a reduced scope for disruption of PPI following sleep deprivation in schizotypes since their (baseline) PPI was already low, there was still sufficient room for PPI disruption (Figure 1). Schizotypes may also be more likely to have unusual sleep experiences in their daily lives (Sheaves et al., 2016), potentially leaving less room for behavioral effects of experimentally-induced sleep deprivation. However, they still showed PPI disruption very similar to those seen in controls, perhaps because having 'unusual sleep patterns' was one of our exclusion criteria. 
We thus believe that a more likely explanation for the absence of an interaction between schizotypy and sleep deprivation is that their effects (i.e. lower PPI in schizotypes and PPI reduction following sleep deprivation) are mediated by different cognitive mechanisms and related to at least partially distinct changes within the neurophysiological startle gating (PPI) circuitry. The effects of schizotypy may be mediated preferentially through prefrontal-striatal-thalamic regions (Kumari et al., 2008). The neural regions underlying PPI-disruptive effect of sleep deprivation have, to our knowledge, not yet been investigated. Further supporting possible involvement of different cognitive mechanisms in schizotypy and sleep deprivation effects in PPI, there are reports of lower PPI accompanied with lower startle amplitude in schizotypes (Simons and Giardina, 1992), but sleep deprivation reduces PPI in humans without affecting startle amplitude (Petrovsky et al., 2014).

Poor attention to task in schizotypes may explain both lower startle amplitude response to pulse-alone stimuli (De la Casa et al., 2016) and lower PPI, especially at medium-to-long (60-ms and 120-ms) prepulse-to-pulse intervals (Dawson et al., 1997). PPI at these intervals is considered to involve controlled processes requiring attention, in addition to automatic processes of stimulus detection and identification (Dawson et al., 1997). PPI reduction following sleep deprivation, on the other hand, may simply reflect impaired processing of the prepulse in both schizotypes and controls. This would also explain the loss of startle amplitude-PPI correlation in schizotypes following sleep deprivation (since it affected only one of the two measures). It is also important to note that schizotypy and sleep deprivation did not interact to affect antisaccade measures of inhibitory control in our earlier study (Meyhöfer et al., 2017b). Further studies of schizotypy and sleep deprivation using attentional PPI paradigms and neuroimaging would help to examine these possibilities. If our assumptions are found to be supported, a combination of schizotypy and sleep deprivation would allow pro-cognitive effects of drugs on different cognitive and neural processes to be investigated concurrently.

A limitation of this study is the small number of males. Accordingly, we were not able to investigate gender differences that are known to influence PPI (Kumari et al., 2003). A second 
limitation is that no corrections for the potential influence of menstrual cycle phase (Jovanovic et al., 2004) could be made because the data were not available.

To conclude, positive schizotypy and sleep deprivation provide human model systems that in combination with the widely studied biomarker PPI can be a useful tool to advance the development of pro-cognitive drugs in the treatment of psychotic disorders. The effects of sleep deprivation and schizotypy in PPI, and possibly other schizophrenia biomarkers, appear to be mediated by different mechanisms. 


\section{REFERENCES}

Abel, K.M., Jolley, S., Hemsley, D.R., Geyer, M.A., 2004. The influence of schizotypy traits on prepulse inhibition in young healthy controls. J. Psychopharmacol. 18, 181-188.

https://doi.org/10.1177/0269881104042617

Barrantes-Vidal, N., Grant, P., Kwapil, T.R., 2015. The role of schizotypy in the study of the etiology of schizophrenia spectrum disorders. Schizophr. Bull. 41, 408-416. https://doi.org/10.1093/schbul/sbu191

Berger, R.J., Oswald, I., 1962. Effects of sleep deprivation on behaviour, subsequent sleep, and dreaming. J. Ment. Sci. 108, 457-465. https://doi.org/10.1192/bjp.108.455.457

Blumenthal, T.D., Creps, C.L., 1994. Normal startle responding in psychosis-prone college students. Pers. Individ. Dif. 17, 345-355. https://doi.org/10.1016/0191-8869(94)90282-8

Braff, D., Stone, C., Callaway, E., Geyer, M., Glick, I., Bali, L., 1978. Prestimulus effects on human startle reflex in normals and schizophrenics. Psychophysiology. https://doi.org/10.1111/j.14698986.1978.tb01390.x

Braff, D.L., Geyer, M.A., 1990. Sensorimotor gating and schizophrenia. Human and animal model studies. Arch. Gen. Psychiatry 47, 181-188. https://doi.org/10.1001/archpsyc.1990.01810140081011

Cadenhead, K.S., Geyer, M.A., Braff, D.L., 1993. Impaired startle prepulse inhibition and habituation in patients with schizotypal personality disorder. Am. J. Psychiatry 150, 1862-1867. https://doi.org/10.1176/ajp.150.12.1862

Cadenhead, K.S., Swerdlow, N.R., Shafer, K.M., Diaz, M., Braff, D.L., 2000. Modulation of the startle response and startle laterality in relatives of schizophrenic patients and in subjects with schizotypal personality disorder: Evidence of inhibitory deficits. Am. J. Psychiatry 157, 16601668. https://doi.org/10.1176/appi.ajp.157.10.1660

Carhart-Harris, R., Brugger, S., Nutt, D.J., Stone, J., 2013. Psychiatry's next top model: cause for a rethink on drug models of psychosis and other psychiatric disorders. J. Psychopharmacol. 27, 771778. https://doi.org/10.1177/0269881113494107

Chang, H.-A., Liu, Y.-P., Tung, C.-S., Chang, C.-C., Tzeng, N.-S., Huang, S.-Y., 2014. Effects of REM sleep deprivation on sensorimotor gating and startle habituation in rats: role of social isolation in early development. Neurosci. Lett. 575, 63-7. https://doi.org/10.1016/j.neulet.2014.05.032 
Cohen, J., 1988. Statistical power analysis for the behavioral sciences (2nd ed.). New York: Academic Press.

Cohen, J., 1973. Eta-squared and partial eta-squared in fixed factor anova designs. Educ. Psychol. Meas. 33, 107-112. https://doi.org/10.1177/001316447303300111

Csomor, P.A., Yee, B.K., Vollenweider, F.X., Feldon, J., Nicolet, T., Quednow, B.B., 2008. On the influence of baseline startle reactivity on the indexation of prepulse inhibition. Behav. Neurosci. 122, 885-900. https://doi.org/10.1037/0735-7044.122.4.885

Dawson, M.E., Schell, A.M., Swerdlow, N.R., Filion, D.L., 1997. Cognitive, clinical, and neuropsychological implications of startle modulation., in: Lang, P., Simons, R., Balaban, M., Mahwah, N. (Eds.), Attention and Orienting: Sensory and Motivational Processes. NJ: Lawrence Erlbaum Associates, pp. 257-279.

De Koning, M.B., Bloemen, O.J.N., Van Duin, E.D.A., Booij, J., Abel, K.M., De Haan, L., Linszen, D.H., Van Amelsvoort, T.A., 2014. Pre-pulse inhibition and striatal dopamine in subjects at an ultrahigh risk for psychosis. J. Psychopharmacol. 28, 553-560. https://doi.org/10.1177/0269881113519507

De la Casa, L.G., Mena, A., Ruiz-Salas, J.C., 2016. Effect of stress and attention on startle response and prepulse inhibition. Physiol. Behav. 165, 179-186.

https://doi.org/10.1016/j.physbeh.2016.07.022

Düring, S., Glenthøj, B.Y., Andersen, G.S., Oranje, B., 2014. Effects of dopamine D2/D3 blockade on human sensory and sensorimotor gating in initially antipsychotic-naive, first-episode schizophrenia patients. Neuropsychopharmacology 39, 3000-3008. https://doi.org/10.1038/npp.2014.152

Ettinger, U., Kumari, V., 2015. Effects of sleep deprivation on inhibitory biomarkers of schizophrenia: implications for drug development. The Lancet Psychiatry 2, 1028-1035. https://doi.org/10.1016/S2215-0366(15)00313-2

Ettinger, U., Meyhöfer, I., Steffens, M., Wagner, M., Koutsouleris, N., 2014. Genetics, cognition, and neurobiology of schizotypal personality: A review of the overlap with schizophrenia. Front. Psychiatry 5, 1-16. https://doi.org/10.3389/fpsyt.2014.00018

Evans, L.H., Gray, N.S., Snowden, R.J., 2005. Prepulse inhibition of startle and its moderation by schizotypy and smoking. Psychophysiology 42, 223-231. https://doi.org/10.1111/j.14698986.2005.00280.x 
Fagerstrom, K.-O., Schneider, N.G., 1989. Measuring nicotine dependence: A review of the Fagerstrom Tolerance Questionnaire. J. Behav. Med. 12, 159-182.

https://doi.org/10.1007/BF00846549

Frau, R., Orrù, M., Puligheddu, M., Gessa, G.L., Mereu, G., Marrosu, F., Bortolato, M., 2008. Sleep deprivation disrupts prepulse inhibition of the startle reflex: reversal by antipsychotic drugs. Int. J. Neuropsychopharmacol. 11, 947-955. https://doi.org/10.1017/S1461145708008900

Geyer, M.A., 2008. Developing translational animal models for symptoms of schizophrenia or bipolar mania. Neurotox. Res. 14, 71-78. https://doi.org/10.1007/BF03033576

Gibbons, R.D., Hedeker, D.R., Davis, J.M., 1993. Estimation of effect size from a series of experiments involving paired comparisons. J. Educ. Stat. 18, 271-279. https://doi.org/10.2307/1165136

Glass, G. V., 1966. Testing homogeneity of variances. Am. Educ. Res. J. 3, 187-190.

Gottesman, I.I., Gould, T.D., 2003. The endophenotype concept in psychiatry: Etymology and strategic intentions. Am. J. Psychiatry 160, 636-645. https://doi.org/10.1176/appi.ajp.160.4.636

Graham, F.K., 1975. The more or less startling effects of weak prestimulation. Psychophysiology. https://doi.org/10.1111/j.1469-8986.1975.tb01284.x

Grant, P., Kuepper, Y., Mueller, E.A., Wielpuetz, C., Mason, O., Hennig, J., 2013. Dopaminergic foundations of schizotypy as measured by the German version of the Oxford-Liverpool Inventory of Feelings and Experiences (O-LIFE)-a suitable endophenotype of schizophrenia. Front. Hum. Neurosci. 7, 1-11. https://doi.org/10.3389/fnhum.2013.00001

Green, M.F., Butler, P.D., Chen, Y., Geyer, M.A., Silverstein, S., Wynn, J.K., Yoon, J.H., Zemon, V., 2009. Perception measurement in clinical trials of schizophrenia: Promising paradigms from CNTRICS. Schizophr. Bull. 35, 163-181. https://doi.org/10.1093/schbul/sbn156

Holm, S., 1979. A simple sequentially rejective multiple test procedure. Scand. J. Stat. 6, 65-70. Jennings, J.R., 1987. Editorial policy on analyses of variance with repeated measurements. Psychophysiology 24, 474-475. https://doi.org/10.1111/j.1469-8986.1987.tb00320.x Jovanovic, T., Szilagyi, S., Chakravorty, S., Fiallos, A.M., Lewison, B.J., Parwani, A., Schwartz, M.P., Gonzenbach, S., Rotrosen, J.P., Duncan, E.J., 2004. Menstrual cycle phase effects on prepulse inhibition of acoustic startle. Psychophysiology 41, 401-406. https://doi.org/10.1111/14698986.2004.00166.x

Kahn-Greene, E.T., Killgore, D.B., Kamimori, G.H., Balkin, T.J., Killgore, W.D.S., 2007. The effects of sleep deprivation on symptoms of psychopathology in healthy adults. Sleep Med. 8, 215-221. 
https://doi.org/10.1016/j.sleep.2006.08.007

Kollar, E.J., Pasnau, R.O., Rubin, R.T., Naitoh, P., Slater, G.G., Kales, A., 1969. Psychological, psychophysiological, and biochemical correlates of prolonged sleep deprivation. Am. J. Psychiatry 126, 488-497. https://doi.org/10.1176/ajp.126.4.488

Kumari, V., Antonova, E., Geyer, M.A., 2008. Prepulse inhibition and "psychosis-proneness" in healthy individuals: An fMRI study. Eur. Psychiatry 23, 274-80. https://doi.org/10.1016/j.eurpsy.2007.11.006

Kumari, V., Checkley, S.A., Gray, J.A., 1996. Effect of cigarette smoking on prepulse inhibition of the acoustic startle reflex in healthy male smokers. Psychopharmacology (Berl). 128, 54-60. https://doi.org/10.1007/s002130050109

Kumari, V., Das, M., Zachariah, E., Ettinger, U., Sharma, T., 2005. Reduced prepulse inhibition in unaffected siblings of schizophrenia patients. Psychophysiology 42, 588-594. https://doi.org/10.1111/j.1469-8986.2005.00346.x

Kumari, V., Fannon, D., Sumich, A.L., Sharma, T., 2007. Startle gating in antipsychotic-naiive first episode schizophrenia patients: One ear is better than two. Psychiatry Res. 151, 21-28. https://doi.org/10.1016/j.psychres.2006.09.013

Kumari, V., Gray, J.A., 1999. Smoking withdrawal, nicotine dependence and prepulse inhibition of the acoustic startle reflex. Psychopharmacology (Berl). 141, 11-15. https://doi.org/10.1007/s002130050800

Kumari, V., Gray, J.A., Gupta, P., Luscher, S., Sharma, T., 2003. Sex differences in prepulse inhibition of the acoustic startle response. Pers. Individ. Dif. 35, 733-742. https://doi.org/10.1016/S01918869(02)00266-0

Kumari, V., Toone, B., Gray, J.A., 1997. Habituation and prepulse inhibition of the acoustic startle reflex: Effects of smoking status and psychosis-proneness. Pers. Individ. Dif. 23, 183-191. https://doi.org/10.1016/S0191-8869(97)00045-7

Lehrl, S., 2005. Mehrfachwahl-Wortschatz-Intelligenztest MWT-B [Multiple Choice Vocabulary Test, version B]., 5th ed. Spitta, Balingen.

Luby, E.D., Grisell, J.L., Frohman, C.E., Lees, H., Cohen, B.D., Gottlieb, J.S., 1962. Biochemical, psychological, and behavioral responses to sleep deprivation. Ann. N. Y. Acad. Sci. 96, 71-79. https://doi.org/10.1111/j.1749-6632.1962.tb50102.x

Ludewig, K., Geyer, M.A., Vollenweider, F.X., 2003. Deficits in prepulse inhibition and habituation in 
never-medicated, first-episode schizophrenia. Biol. Psychiatry 54, 121-128.

https://doi.org/10.1016/S0006-3223(02)01925-X

Mason, O., Claridge, G., Jackson, M., 1995. New scales for the assessment of schizotypy. Pers. Individ. Dif. 18, 7-13. https://doi.org/10.1016/0191-8869(94)00132-C

Mason, O., Linney, Y., Claridge, G., 2005. Short scales for measuring schizotypy. Schizophr. Res. 78, 293-6. https://doi.org/10.1016/j.schres.2005.06.020

Mason, O.J., Morgan, C.J.M., Stefanovic, A., Curran, H. V, 2008. The Psychotomimetic States Inventory (PSI): Measuring psychotic-type experiences from ketamine and cannabis. Schizophr. Res. 103, 138-142. https://doi.org/10.1016/j.schres.2008.02.020

Meyhöfer, I., Kumari, V., Hill, A., Petrovsky, N., Ettinger, U., 2017a. Sleep deprivation as an experimental model system for psychosis: Effects on smooth pursuit, prosaccades, and antisaccades. J. Psychopharmacol. 31, 418-433. https://doi.org/10.1177/0269881116675511

Meyhöfer, I., Steffens, M., Faiola, E., Kasparbauer, A.-M., Kumari, V., Ettinger, U., 2017b. Combining two model systems of psychosis: The effects of schizotypy and sleep deprivation on oculomotor control and psychotomimetic states. Psychophysiology 1-15. https://doi.org/10.1111/psyp.12917

Neill, E., 2014. Methodological considerations in the recruitment and analysis of schizotypy samples. Front. Psychiatry 5, 1-3. https://doi.org/10.3389/fpsyt.2014.00156

Nelson, M.T., Seal, M.L., Pantelis, C., Phillips, L.J., 2013. Evidence of a dimensional relationship between schizotypy and schizophrenia: A systematic review. Neurosci. Biobehav. Rev. 37, 317327. https://doi.org/10.1016/j.neubiorev.2013.01.004

Petrovsky, N., Ettinger, U., Hill, A., Frenzel, L., Meyhöfer, I., Wagner, M., Backhaus, J., Kumari, V., 2014. Sleep deprivation disrupts prepulse inhibition and induces psychosis-like symptoms in healthy humans. J. Neurosci. 34, 9134-9140. https://doi.org/10.1523/JNEUROSCI.0904-14.2014

Petrovsky, N., Ettinger, U., Kessler, H., Mössner, R., Wolfsgruber, S., Dahmen, N., Maier, W., Wagner, M., Quednow, B.B., 2013. The effect of nicotine on sensorimotor gating is modulated by a CHRNA3 polymorphism. Psychopharmacology (Berl). 229, 31-40. https://doi.org/10.1007/s00213-013-3081-1

R Core Team, 2016. R: A Language and Environment for Statistical Computing.

Raine, A., Reynolds, C., Lencz, T., Scerbo, A., Triphon, N., Kim, D., 1994. Cognitive-perceptual, interpersonal, and disorganized features of schizotypal personality. Schizophr. Bull. 20, 191- 
201. https://doi.org/10.1093/schbul/20.1.191

Shapiro, S.S., Wilk, M.B., 1965. An analysis of variance test for normality (complete samples). Biometrika 52, 591. https://doi.org/10.2307/2333709

Sheaves, B., Bebbington, P.E., Goodwin, G.M., Harrison, P.J., Espie, C.A., Foster, R.G., Freeman, D., 2016. Insomnia and hallucinations in the general population: Findings from the 2000 and 2007 British Psychiatric Morbidity Surveys. Psychiatry Res. 241, 141-146.

https://doi.org/10.1016/j.psychres.2016.03.055

Sheehan, D. V., Lecrubier, Y., Sheehan, K.H., Amorim, P., Janavs, J., Weiller, E., Hergueta, T., Baker, R., Dunbar, G.C., 1998. The Mini-International Neuropsychiatric Interview (M.I.N.I): The development and validation of a structured diagnostic psychiatric interview for DSM-IV and ICD10. J. Clin. Psychiatry 59, 22-33.

Simons, R.F., Giardina, B.D., 1992. Reflex modification in psychosis-prone young adults. Psychophysiology 29, 8-16. https://doi.org/10.1111/j.1469-8986.1992.tb02004.x

Swerdlow, N.R., Filion, D., Geyer, M.A., Braff, D.L., 1995. “Normal” personality correlates of sensorimotor, cognitive, and visuospatial gating. Biol. Psychiatry 37, 286-99. https://doi.org/10.1016/0006-3223(94)00138-S

Swerdlow, N.R., Light, G.A., Cadenhead, K.S., Sprock, J.B., Hsieh, M.H., Braff, D.L., 2006. Startle gating deficits in a large cohort of patients with schizophrenia. Arch. Gen. Psychiatry 63, 1325-1335. https://doi.org/10.1001/archpsyc.63.12.1325

Swerdlow, N.R., Light, G.A., Sprock, J., Calkins, M.E., Green, M.F., Greenwood, T.A., Gur, R.E., Gur, R.C., Lazzeroni, L.C., Nuechterlein, K.H., Radant, A.D., Ray, A., Seidman, L.J., Siever, L.J., Silverman, J.M., Stone, W.S., Sugar, C.A., Tsuang, D.W., Tsuang, M.T., Turetsky, B.I., Braff, D.L., 2014. Deficient prepulse inhibition in schizophrenia detected by the multi-site COGS. Schizophr. Res. 152, 503-512. https://doi.org/10.1016/j.schres.2013.12.004

Swerdlow, N.R., Weber, M., Qu, Y., Light, G.A., Braff, D.L., 2008. Realistic expectations of prepulse inhibition in translational models for schizophrenia research. Psychopharmacology (Berl). 199, 331-388. https://doi.org/10.1007/s00213-008-1072-4

Takahashi, H., Iwase, M., Canuet, L., Yasuda, Y., Ohi, K., Fukumoto, M., like, N., Nakahachi, T., Ikezawa, K., Azechi, M., Kurimoto, R., Ishii, R., Yoshida, T., Kazui, H., Hashimoto, R., Takeda, M., 2010. Relationship between prepulse inhibition of acoustic startle response and schizotypy in healthy Japanese subjects. Psychophysiology 47, 831-837. https://doi.org/10.1111/j.14698986.2010.01000.x 
Torchiano, M., 2016. effsize: Efficient Effect Size Computation. R package version 0.7.0.

West, L.J., Janszen, H.H., Lester, B.K., Cornelisoon, F.S., 1962. The psychosis of sleep deprivation. Ann. N. Y. Acad. Sci. 96, 66-70. https://doi.org/10.1111/j.1749-6632.1962.tb50101.x

Ziermans, T., Schothorst, P., Magnée, M., Van Engeland, H., Kemner, C., 2011. Reduced prepulse inhibition in adolescents at risk for psychosis: a 2-year follow-up study. J. Psychiatry Neurosci. 36, 127-134. https://doi.org/10.1503/jpn.100063 


\section{Figure Legends}

Figure 1. The figure shows untransformed mean scores [ \pm standard errors of the mean] of \% PPI separated by schizotypy group. Effect sizes are given using Cohen's $d$ (Cohen, 1988). $n_{\text {controls }}=12 . n_{\text {schizotypes }}=12$.

Figure 2. Correlations between \% PPI and pulse-alone startle amplitude (averaged over blocks 2-4) separated by schizotypy group and condition. Linear trend line and $R^{2}$ refer to the high schizotypy group. $n_{\text {controls }}=12$. $n_{\text {schizotypes }}=12$. 


\section{TABLES}

Table 1. Overview of Demographic and Personality Measures

\begin{tabular}{|c|c|c|c|}
\hline & Controls & Schizotypes & Statistics \\
\hline$n$ & 12 & 12 & \\
\hline Age $(S D)$ & $26.17(6.37)$ & $26.58(9.13)$ & $T(22)=0.13, p=.90$ \\
\hline Gender ( $n$ female/male) & $7 / 5$ & $9 / 3$ & $\chi^{2}(1)=0.75, p=.39$ \\
\hline Order ( $n$ sleep first/wake first) & $8 / 4$ & $6 / 6$ & $\chi^{2}(1)=0.69, p=.41$ \\
\hline MWT-B Score (SD) & 30.67 (3.47) & $29.42(3.63)$ & $T(22)=0.86, p=.40$ \\
\hline Unusual Experiences (SD) & $2.08(0.79)$ & $10.08(1.08)$ & $T(22)=20.64, p<.001$ \\
\hline Introvertive Anhedonia $(S D)$ & $0.83(0.39)$ & $1.08(1.00)$ & $T(14.28)=0.81, p=.43$ \\
\hline Cognitive Disorganization $(S D)^{1}$ & $4.42(2.91)$ & $8.33(2.39)$ & $T(22)=3.61, p=.002$ \\
\hline Impulsive Nonconformity $(S D)^{1}$ & $3.25(1.82)$ & $5.83(1.90)$ & $T(22)=3.41, p=.003$ \\
\hline Smoker ( $n$ yes/no) & $1 / 11$ & $4 / 8$ & $\chi^{2}(1)=2.27, p=.13$ \\
\hline $\begin{array}{l}N \text { cigarettes per day }{ }^{2} \\
\text { (Fagerström Score; Fagerstrom and } \\
\text { Schneider, 1989) }\end{array}$ & $10.00(1.00)$ & $9.50(1.50)$ & \\
\hline
\end{tabular}

Notes. ${ }^{1}$ In order to give an overview, results for all O-LIFE subscales are shown. ${ }^{2}$ Only regularly smoking participants are considered. Due to the small number of smoking participants, no inferential statistics were computed. $S D=$ standard deviation. MWT-B=Mehrfachwahl-Wortschatz-Intelligenztest, Version B (Lehrl, 2005). Data are means unless indicated otherwise. 
Table 2. Descriptive Statistics of Startle Amplitude, Habituation, and \% PPI

Startle Amplitude over Pulse-alone Trials: Normal Sleep

\begin{tabular}{lccccc}
\hline & Block 1 & Block 2 & Block 3 & Block 4 & Block 5 \\
\hline controls & $867.68(560.28)$ & $650.56(450.64)$ & $472.11(471.57)$ & $493.11(467.02)$ & $530.91(560.79)$ \\
schizotypes & $398.98(257.32)$ & $261.07(237.27)$ & $169.56(157.43)$ & $147.31(130.05)$ & $139.83(93.36)$ \\
\hline
\end{tabular}

Startle Amplitude over Pulse-alone Trials: Sleep Deprivation

\begin{tabular}{lccccc}
\hline & Block 1 & Block 2 & Block 3 & Block 4 & Block 5 \\
\hline controls & $673.84(516.07)$ & $498.35(484.26)$ & $432.70(603.89)$ & $362.85(389.79)$ & $399.68(475.69)$ \\
schizotypes & $415.81(264.67)$ & $235.42(190.07)$ & $137.75(83.66)$ & $107.93(74.44)$ & $117.29(88.40)$ \\
\hline
\end{tabular}

Habituation Measures

\begin{tabular}{llllll}
\hline Normal Sleep & \multicolumn{5}{l}{ Sleep Deprivation } \\
\hline early & total & coefficient & early & total & coefficient \\
\hline $25.74(32.16)$ & $51.25(23.99)$ & $-81.99(67.02)$ & $27.68(52.96)$ & $58.21(23.88)$ & $-78.55(71.81)$ \\
\hline
\end{tabular}

PPI (\%): Normal Sleep

\begin{tabular}{llll}
\hline & $30 \mathrm{~ms}$ & $60 \mathrm{~ms}$ & $120 \mathrm{~ms}$ \\
\hline controls & $30.13(25.17)$ & $72.25(19.40)$ & $77.90(14.14)$ \\
schizotypes & $20.80(25.40)$ & $53.32(23.47)$ & $56.98(23.32)$ \\
\hline
\end{tabular}

PPI (\%): Sleep Deprivation

\begin{tabular}{llll}
\hline & $30 \mathrm{~ms}$ & $60 \mathrm{~ms}$ & $120 \mathrm{~ms}$ \\
\hline controls & $18.57(33.08)$ & $64.97(16.28)$ & $66.87(21.41)$ \\
schizotypes & $18.69(27.23)$ & $46.96(29.06)$ & $47.20(27.57)$ \\
\hline
\end{tabular}

Notes. Data represent untransformed means (standard deviations). Startle amplitude is depicted in arbitrary units ( 1 unit $=2.62 \mu \mathrm{V}$ ). Startle amplitude over pulse-alone trials: $n_{\text {controls }}=9, n_{\text {schizotypes }}=12$. PPI, total habituation, and habituation coefficient b: $n_{\text {controls }}=12, n_{\text {schizotypes }}=12$. Early habituation: $n_{\text {controls }}=11, n_{\text {schizotypes }}=12$. 
Table 3. Cohen's d for the Effects of Sleep Deprivation on \% PPI

\begin{tabular}{lccc}
\hline & $\begin{array}{c}\text { Petrovsky et al (2014) } \\
\mathbf{N = 2 4}\end{array}$ & $\begin{array}{c}\text { Current Study } \\
\mathbf{N = 2 4}\end{array}$ & $\begin{array}{c}\text { Effect size averaged } \\
\text { over the two studies }\end{array}$ \\
\hline $\mathbf{3 0 m s}$ SOA & 0.54 & $0.19^{1}$ & 0.37 \\
\hline $\mathbf{6 0 m s ~ S O A}$ & 1.12 & $0.31^{2}$ & 0.72 \\
\hline $\mathbf{1 2 0 m s ~ S O A}$ & 0.38 & $0.50^{3}$ & 0.44 \\
\hline
\end{tabular}

Notes. Data represent Cohen's d scores (Gibbons et al., 1993). Effect sizes separated by group ( $n=12$ schizotypes, $n=12$ controls) are as follows: ${ }^{1}$ schizotypes: 0.07 , controls: $0.29 ;^{2}$ schizotypes: 0.25 , controls: 0.38 ; ${ }^{3}$ schizotypes: 0.69 , controls: 0.42 . 


\section{FIGURES}

Figure 1.

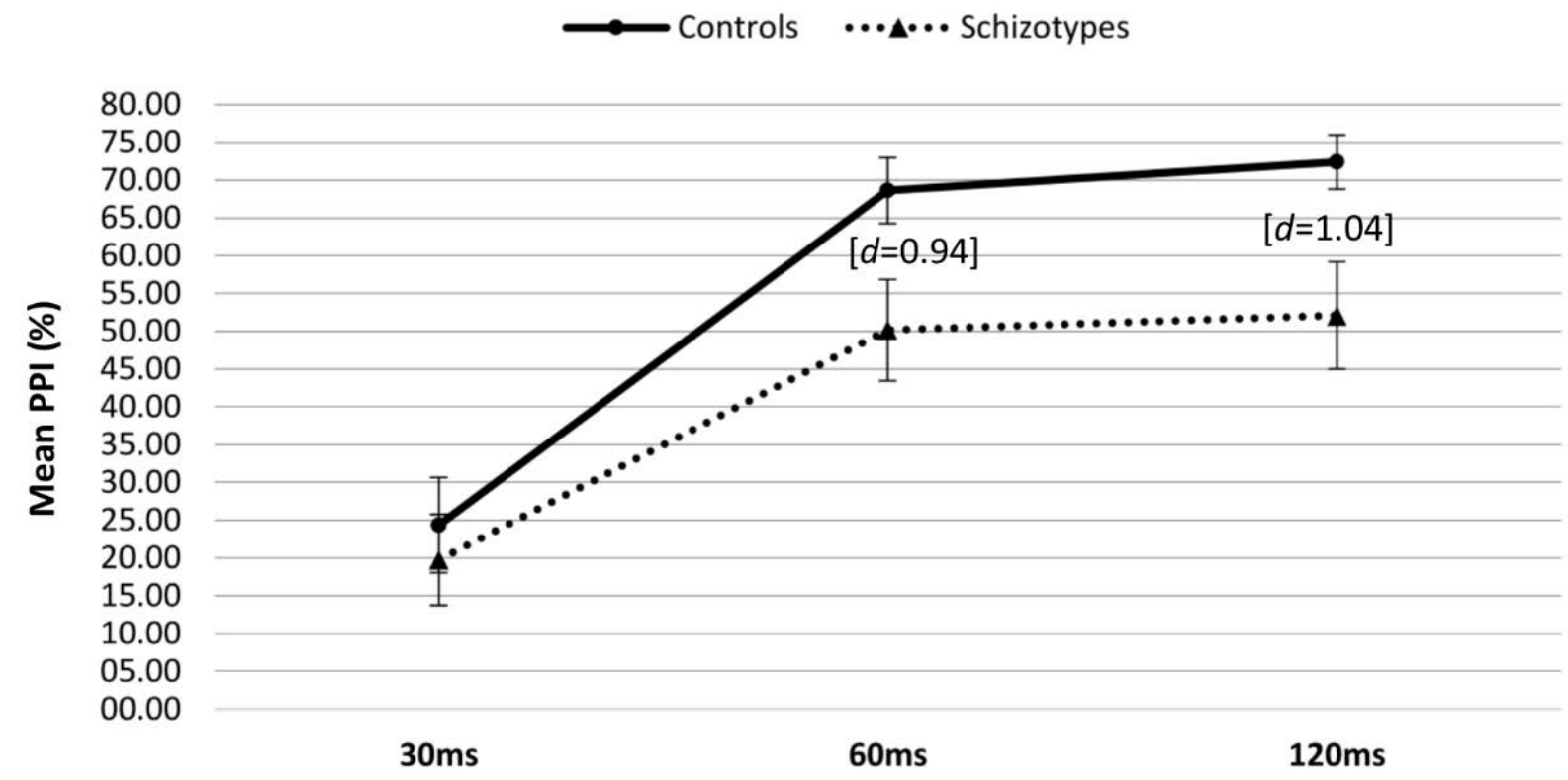


Figure 2.

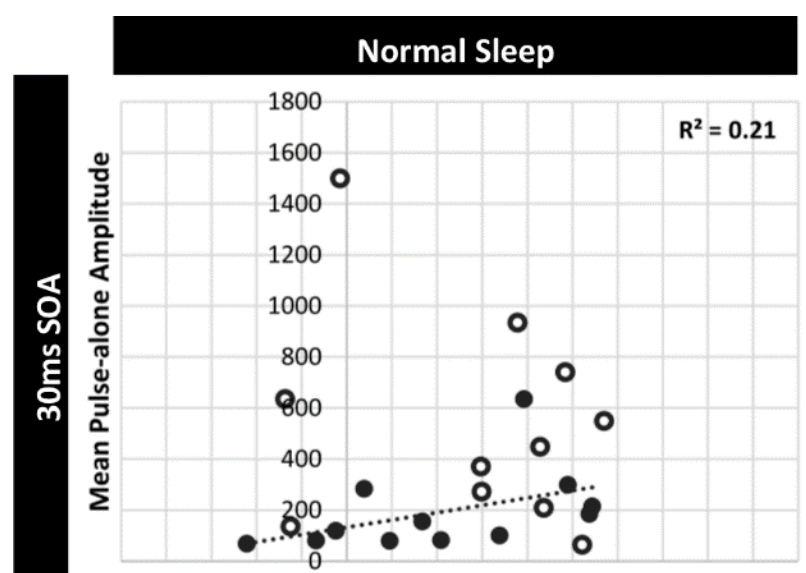

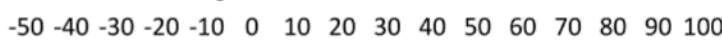
PPI (\%)

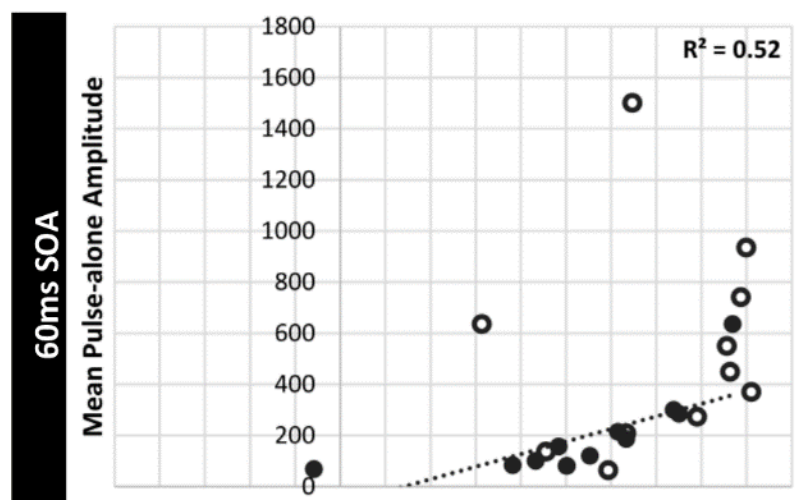

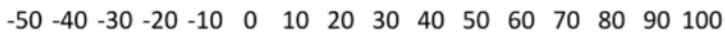
PPI (\%)
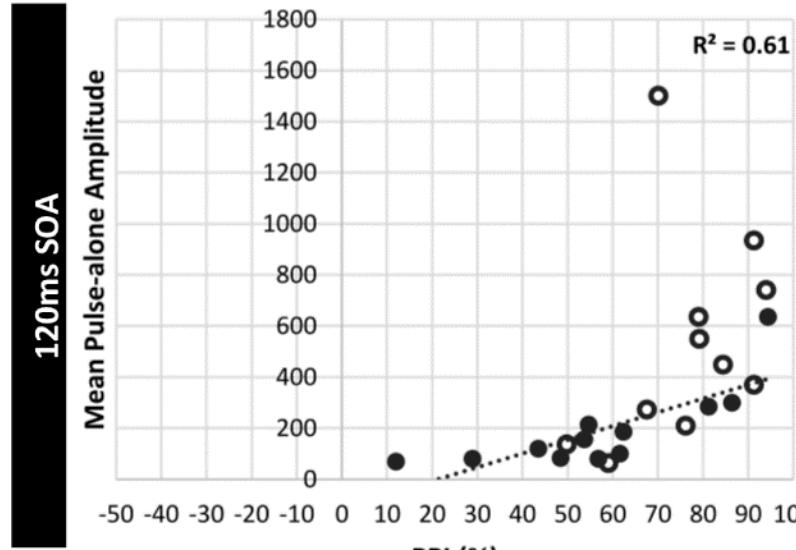

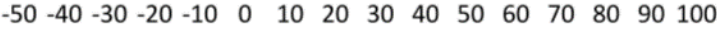
PPI (\%)

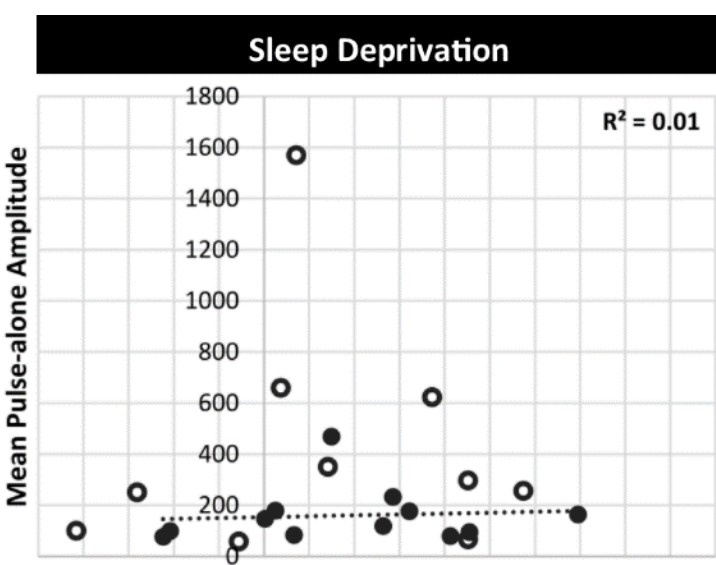

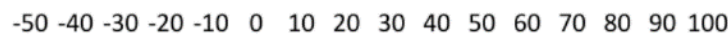
PPI (\%)

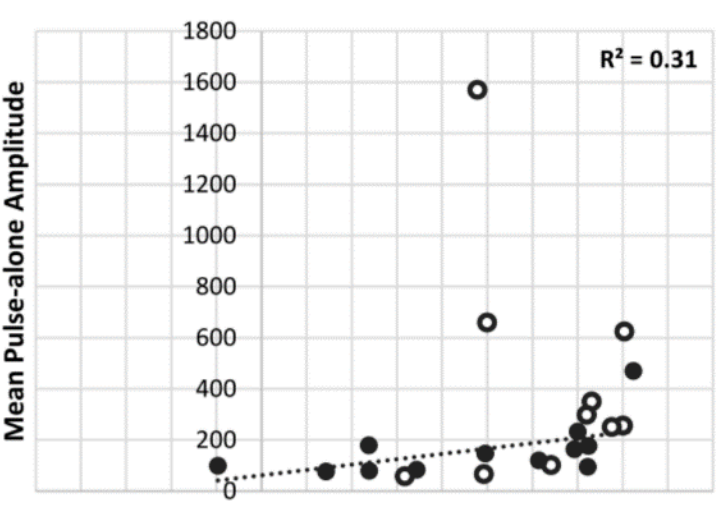

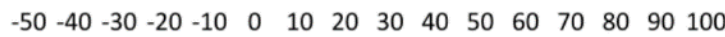
PPI (\%)

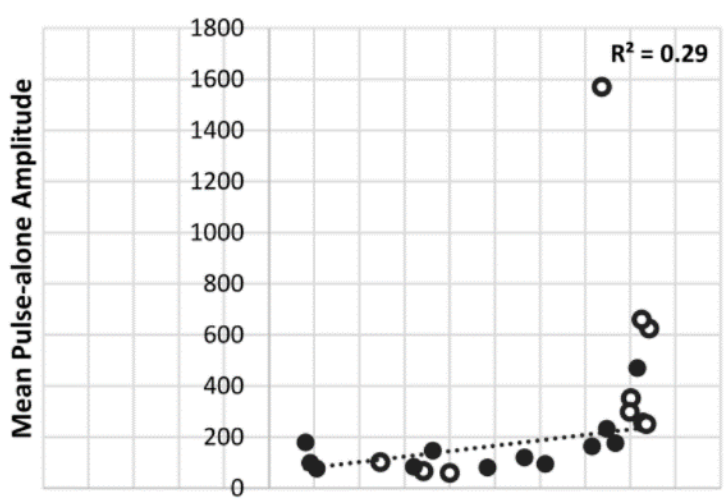

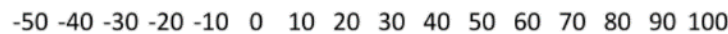
PPI (\%)

- Controls

- Schizotypes 


\section{The effects of schizotypy and sleep deprivation on prepulse inhibition}

Inga Meyhöfer (1,2), Ulrich Ettinger (1)*, Eliana Faiola (1), Nadine Petrovsky (1), Veena Kumari (3)

(1) Department of Psychology, University of Bonn, Bonn, Germany

(2) Department of Psychiatry, University of Münster, Münster, Germany

(3) Centre for Cognitive Neuroscience, College of Health and Life Sciences, Brunel University London, Uxbridge, UK

\section{*Correspondence:}

Ulrich Ettinger, Department of Psychology, University of Bonn, Kaiser-Karl-Ring 9, 53111 Bonn,

Germany, Email: ulrich.ettinger@uni-bonn.de, Phone: +49 228734208 


\section{Supplementary Results [Psychotomimetic States]}

The PSI subscales Delusional Thinking, Perceptual Distortion, Anhedonia, Mania, and Paranoia were markedly skewed and had to be log transformed in order to reach approximate normality.

\section{Effects of Schizotypy}

Main effects of Group indicated higher scores for high schizotypes than controls on Delusional Thinking $\left(F[1,22]=18.82, p<.001, \eta_{p}{ }^{2}=0.46\right)$, Perceptual Distortion $(F[1,22]=18.13, p<.001$, $\left.\eta_{\mathrm{p}}{ }^{2}=0.45\right)$, Cognitive Disorganization $\left(F[1,22]=17.18, p<.001, \eta_{\mathrm{p}}{ }^{2}=0.44\right)$, Anhedonia $(F[1,22]=5.74$, $\left.p=.03, \eta_{\mathrm{p}}{ }^{2}=0.21\right)$, Mania $\left(F[1,22]=6.33, p=.02, \eta_{\mathrm{p}}{ }^{2}=0.22\right)$, and Paranoia $(F[1,22]=6.56, p=.02$, $\left.\eta_{\mathrm{p}}{ }^{2}=0.23\right)$

\section{Effects of Sleep Deprivation}

Effects of sleep deprivation were detected by interactions between Condition and Time in Perceptual Distortion $\left(F[1,22]=6.33, p=.02, \eta_{\mathrm{p}}{ }^{2}=0.22\right)$, Cognitive Disorganization $(F[1,22]=13.32$, $\left.p=.001, \eta_{\mathrm{p}}{ }^{2}=0.38\right)$, and Anhedonia $\left(F[1,22]=6.24, p=.02, \eta_{\mathrm{p}}{ }^{2}=0.22\right)$. Thus, Perceptual Distortion and Cognitive Disorganization were higher in the morning after sleep deprivation than normal sleep (Perceptual Distortion: $p=.04, d=0.52$; Cognitive Disorganization: $p=.004, d=0.77$ ) and in the morning after sleep deprivation compared to the evening before sleep deprivation (Perceptual Distortion: $p=.04, d=0.50$; Cognitive Disorganization: $p=.008, d=0.63$ ). However, post hoc tests did not reach significance for the Anhedonia subscale (sleep deprivation morning $=$ normal sleep $_{\text {morning }}: p=.16, d=0.42$; sleep deprivation $_{\text {evening }}=$ sleep deprivation $\left._{\text {morning }}: p=.15, d=0.47\right)$. Effects of Time of Day

Main effects of Time suggested lower scores in the morning than the evening for Delusional Thinking $\left(F[1,22]=12.92, p=.002, \eta_{\mathrm{p}}{ }^{2}=0.37\right)$ and Paranoia $\left(F[1,22]=29.85, p<.001, \eta_{\mathrm{p}}{ }^{2}=0.58\right)$. 
Supplementary Table 1. Overview of Participant Selection.

\begin{tabular}{lcccc}
\hline & & \multicolumn{2}{c}{ Gender } \\
\hline Completed O-LIFE Online & & Number & female & male \\
\hline Contacted via E-Mail & & $5006^{2}$ & 3354 & 1652 \\
\hline Screened via Telephone & controls & 547 & 394 & 180 \\
& schizotypes & 194 & 148 & 46 \\
\hline Participated in Session 1 & controls & 37 & 25 & 12 \\
(including PPI) & schizotypes & 38 & 28 & 10 \\
\hline Participated in Session 2 & controls & 18 & 11 & 7 \\
(including PPI) & cchizotypes & 16 & 12 & 4 \\
\hline Subsample Reported in the & schizotypes & 18 & 11 & 7 \\
Current Study & controls & 15 & 11 & 4 \\
\hline Notes. ${ }^{-O}$ schizotypes & 12 & 9 & 5 \\
\hline
\end{tabular}

Notes. ${ }^{1}$ Only subjects aged $18-50$ were included. A total of 4685 subjects provided contact information (female: $n=3123$; male: $n=1562$ ). ${ }^{2}$ Only subjects that met O-LIFE inclusion criteria were contacted. 
Supplementary Table 2. Summary of ANOVA Results for Startle Amplitude over Pulse-alone Trials.

\begin{tabular}{|c|c|c|c|c|c|c|c|}
\hline Variable & Condition & Block & Group & $\begin{array}{l}\text { Condition } \\
\text { *Block }\end{array}$ & Block*Group & $\begin{array}{l}\text { Condition } \\
\text { *Group }\end{array}$ & $\begin{array}{l}\text { Condition*Block } \\
\text { *Group }\end{array}$ \\
\hline Startle Amplitude ${ }^{1}$ & $\begin{array}{l}F[1,19]=2.28 \\
p=.15, \eta_{\mathrm{p}}^{2}=0.11\end{array}$ & $\begin{array}{l}F[4,76]=55.02, \\
p<.001, \eta_{p}^{2}=0.74\end{array}$ & $\begin{array}{l}F[1,19]=6.46, \\
p=.02, \eta_{p}^{2}=0.25\end{array}$ & $\begin{array}{l}F[4,76]=0.30 \\
\varepsilon=0.67, p=.80 \\
\eta_{\mathrm{p}}{ }^{2}=0.02\end{array}$ & $\begin{array}{l}F[4,76]=1.44 \\
p=.23, \eta_{\mathrm{p}}{ }^{2}=0.07\end{array}$ & $\begin{array}{l}F[1,19]=0.75 \\
p=.40, \eta_{p}^{2}=0.04\end{array}$ & $\begin{array}{l}F[4,76]=0.24, \\
\varepsilon=0.67, p=.85, \\
\eta_{p}^{2}=0.01\end{array}$ \\
\hline
\end{tabular}

Notes. ${ }^{1}$ Due to high positive skewness log-transformed values were used for analyses. Condition=normal sleep, sleep deprivation. Block=1, 2, 3, 4, 5. Group=controls, schizotypes. Significant results are printed in bold type. $n_{\text {controls }}=9 . n_{\text {schizotypes }}=12$. 
Supplementary Table 3. Summary of ANOVA Results for Habituation Measures.

\begin{tabular}{llll}
\hline Variable & Condition & Group & Condition \\
& & & *Goup $^{*}$ \\
\hline Early & $F[1,21]=0.02$, & $F[1,21]=0.10$, & $F[1,21]=0.03$, \\
Habituation & $p=.89, \eta_{\mathrm{p}}{ }^{2}=0.00$ & $p=.76, \eta_{\mathrm{p}}{ }^{2}=0.01$ & $p=.86, \eta_{\mathrm{p}}{ }^{2}=0.00$ \\
\hline Total & $F[1,22]=1.46$, & $F[1,22]=1.41$, & $F[1,22]=0.07$, \\
Habituation & $p=.24, \eta_{\mathrm{p}}{ }^{2}=0.06$ & $p=.25, \eta_{\mathrm{p}}{ }^{2}=0.06$ & $p=.79, \eta_{\mathrm{p}}{ }^{2}=0.00$ \\
\hline Habituation Coefficient & $F[1,22]=0.03$, & $F[1,22]=1.35$, & $F[1,22]=0.46$, \\
& $p=.86, \eta_{\mathrm{p}}{ }^{2}=0.00$ & $p=.26, \eta_{\mathrm{p}}{ }^{2}=0.06$ & $p=.50, \eta_{\mathrm{p}}{ }^{2}=0.02$ \\
\hline
\end{tabular}

Notes. Condition=normal sleep, sleep deprivation. Group=controls, schizotypes. Significant results are printed in bold type. Early habituation: $n_{\text {controls }}=11 . n_{\text {schizotypes }}=12$. Total habituation: $n_{\text {controls }}=12 . n_{\text {schizotypes }}=12$. Habituation coefficient $b: n_{\text {controls }}=12 . n_{\text {schizotypes }}=12$. 
Supplementary Table 4. Summary of PPI ANOVA Results.

\begin{tabular}{|c|c|c|c|c|c|c|c|}
\hline Variable & Condition & SOA & Group & $\begin{array}{l}\text { Condition } \\
\text { *SOA }\end{array}$ & SOA*Group & $\begin{array}{l}\text { Condition } \\
\text { *Group }\end{array}$ & $\begin{array}{l}\text { Condition*SOA } \\
\text { *Group }\end{array}$ \\
\hline PPI (\%) & $\begin{array}{l}F[1,22]=3.60 \\
p=.07, \eta_{\mathrm{p}}^{2}=0.14\end{array}$ & $\begin{array}{l}F[2,44]=109.36 \\
p<.001, \eta_{p}{ }^{2}=0.83\end{array}$ & $\begin{array}{l}F[1,22]=3.77 \\
p=.07, \eta_{\mathrm{p}}{ }^{2}=0.15\end{array}$ & $\begin{array}{l}F[2,44]=0.22 \\
\varepsilon=0.65, p=.71 \\
\eta_{\mathrm{p}}^{2}=0.01\end{array}$ & $\begin{array}{l}F[2,44]=4.00 \\
p=.03, \eta_{\mathrm{p}}^{2}=0.15\end{array}$ & $\begin{array}{l}F[1,22]=0.21, \\
p=.65, \eta_{p}^{2}=0.01\end{array}$ & $\begin{array}{l}F[2,44]=0.29 \\
\varepsilon=0.65, p=.65 \\
\eta_{\mathrm{p}}^{2}=0.01\end{array}$ \\
\hline
\end{tabular}

Notes. PPI=prepulse inhibition. SOA=stimulus onset asynchrony. Condition=normal sleep, sleep deprivation. SOA=30ms, $60 \mathrm{~ms}$, $120 \mathrm{~ms}$. Group=controls, schizotypes. Significant results are printed in bold type. $n_{\text {controls }}=12 . n_{\text {schizotypes }}=12$. 
Supplementary Table 5. Correlations between Startle Amplitude and PPI.

\begin{tabular}{|c|c|c|c|}
\hline & $30 \mathrm{~ms}$ SOA & $60 \mathrm{~ms}$ SOA & $120 \mathrm{~ms} S O A$ \\
\hline \multicolumn{4}{|c|}{ Normal Sleep } \\
\hline Controls & $\tau=-.13(.59)$ & $\tau=.31(.19)$ & $\tau=.38(.10)$ \\
\hline \multicolumn{4}{|c|}{ Sleep Deprivation } \\
\hline Controls & $\tau=.02(.93)$ & $\tau=.20(.42)$ & $\tau=.24(.33)$ \\
\hline
\end{tabular}

Notes. PPI=prepulse inhibition. SOA=stimulus onset asynchrony. Correlations that remain significant after Bonferroni-Holm correction for multiple testing are printed in bold. Kendall's $\mathrm{\tau}$ was applied due to violation of normality for startle amplitude scores. 